\title{
Effect of Low Level Laser Therapy (LLLT) on Pain, Trismus and Quality of Life (QOL) in Post Lower Third Molar Removal Patients : A Randomized Controlled Trial
}

\author{
Andi Dala Intan ${ }^{1}$, Nyoman Murdana ${ }^{1}$, SA Nuhonni ${ }^{1}$, Lilies Dwi ${ }^{2}$ \\ ${ }^{1}$ Department of Physical Medicine and Rehabilitation, Cipto Mangunkusumo General Hospital, \\ Faculty of Medicine, University of Indonesia, Jakarta, Indonesia \\ ${ }^{2}$ Department of Oromaxillofacial Surgery, Faculty of Dentistry, University of Indonesia, \\ Jakarta, Indonesia
}

\begin{abstract}
Background: Low-Level Laser Therapy (LLLT) is a physical modality used in a rehabilitation support service. Patients with lower third molar impacted experience decline in QOL due to inflamatory response, such as bleeding, swelling, stiffness and pain. This leads to disability in daily activities, such as eating and drinking during several days post removal.

Methods: It is a randomized controlled trial (RCT) and single blind study. A total of 21 subjects in LLLT and 21 subjects in control groups with the age range of 18-30 years. Subjects in the study group were given a total dose of $54 \mathrm{~J}$, energy density $18 \mathrm{~J} / \mathrm{cm}^{2}$ on day 0,3 and 7 post lower third molar impacted surgery. Both groups were assessed for QOL values using the Short Form 36 (SF-36) before and after therapy.

Result: Decrease in Pain (VAS) and Trismus on the third and seventh day post operatively were statistically significant $(\mathrm{p}<0.05)$ between the two groups. QOL improvement on the SF-36 domains of Role Physically (RP), Bodily Pain (BP), General Health (GH) was statistically significant $(\mathrm{p}<0.05)$ in both groups. Moreover, QOL improvement in Physical Components (PCS) was also significant between the two groups.

Conclusion: LLLT could reduce postoperative pain of lower third molar impacted patients from day 0 to 3 and completely painless on the seventh day postoperatively. LLLT therapy eliminated Trismus on the third day after the surgey. Increase QOL in patients with lower third molar impacted removal after LLLT was evident in the physical component. The positive changes in pain and trismus reduction, also QOL improvement post LLLT can restore patients' activities of daily living as usual in a short period of time.
\end{abstract}

Keywords : Low Level Laser Therapy (LLLT), Pain, Trismus, Quality of Life, Rehabilitation, Lower Third Molar Removal.

Received in March 2016 and accepted for publication in April 2016.

Correspondence Detail: Andi Dala Intan.

Taman Buaran Indah I Block E No.128 AB, Klender, East Jakarta 13470, Indonesia

Email: dalabatara82@gmail.com

Phone: +6281524345177

\section{INTRODUCTION}

Laser is an acronym of Light Amplification of Stimulated Emission of Radiation. Albert Einstein (1971) introduces the concept of physical emission when it is stimulated, it produces photochemical reaction with minimal thermal effect. Low-level Laser Therapy (LLLT) 
is the application of light in pathological tissue to stimulate regeneration, act as anti inflammation, increase of serotonin and endorphin production to alleviate the pain. In these narrow width light spectrum, there are red and near infra red spectrum $(600-1100 \mathrm{~nm})$ with a power density between $1 \mathrm{mw}-5 \mathrm{~W} / \mathrm{cm}^{2}{ }^{1}$

LLLT is a physical modality used as a supportive medical therapy and play a role in medical rehabilitation service. Clinicians in Europe, Asia, and North America have proved the benefits of using this therapy. Nowadays, laser is a well-known therapy modality because it has many positive effects on tissue damage, especially in human. LLLT can be used as an adjuvant therapy in many dentistry cases, suca as reducing dentin hypersensitivity, disorder of temporomandibular joint, oral mucositis, injury of alveolar nerve, and post teeth dissection. ${ }^{2}$

Molar impaction occurs when a tooth fails to erupt into the dental arch in the range of estimated time. It is because the molar reside in a layer of solid bone, or thick soft tissue that hinders the eruption. Extraction is needed in this case; otherwise, molar will be restrained lifetime. ${ }^{3}$ Molar impaction affects all races, including Caucasian. According to Coulthard et al. (2003), as soon as age 18 will begin molar eruption with $30-50 \%$ chances for complete eruption at 25 years old whereas 50 $70 \%$ has impaction. The third molar impaction prevalence in Iran varies from $16.7 \%$ to $68.6 \%$. Additionally, most studies explain that there are no dominant predilection based on sex, but some studies show woman is at higher risk to develop impaction. ${ }^{4}$ In 2012, Cipto Mangunkusumo National Hospital received 263 patients in the mouth and teeth clinic for extraction due to molar impaction. Moreover, the Dentistry Hospital, Facullty of Dentistry University of
Indonesia recorded 311 cases from June 2009May 2010, and even higher on June 2010 - May $2011 .{ }^{5}$ The surgery procedure on the third molar is called Odontectomy that is often performed in the Division of Oral Surgery.

There are many pathological changes in patient with impaction, such as inflamation in the surrounding soft tissue, roots resorption, disease of alveolar bone and soft tissues, adjacent tooth decay, caries, and even head or jaw pain. Clinical manifestations include chewing and eating process disruption. Thus, extraction is required to overcome the pathological changes. Post surgical complains that often experienced by patients include pain, edema, and reduce of temporomandibular joint function. ${ }^{6-8}$

Despite of many contributing factors, inflammation process is actually the main reason to initiate the traumatic surgery. ${ }^{6-7}$ Quality of life (QOL) reduction can be happened after the operation of third molar impaction. This is because of some physiological responses caused, such as bleeding, swelling, stiffness, and pain. As a consequence, restrain of daily activities is common, such as eat and drink. The most evident QOL disturbance due to major complains occurs in the first 7 days post-surgery. ${ }^{9}$ The most painful period is during the first 3-5 hours after the cessation of local anesthetic effect. Edema usually reaches the peak during the first 24-48 hours and decrease gradually for the next days before it dissapears on next 5-7 days. ${ }^{3}$ Trismus disappears on the third days, pain ends on the seventh days with the aids of antibiotic and nonsteroid anti inflammatory drug (NSAID) for 5 days. ${ }^{3,6,10}$

The success of therapy can be assessed when symptoms and signs associated with the third molar, such as discomfort, swelling, and trismus 
or during normal healing have disappeared and the tissue is fully recovered without remaining functional deficits. Such symptoms gradually disappear in the next 2 weeks after surgery. ${ }^{11}$

WHO has defined QOL as “....an individual's perception of their position in life in the context of the culture and value system of which they live with the relation to their goals, expectations, standars and concerns." This concept is related to various individual aspects, which include physical health, psychological states, the independence, social relationship, confidence and relation between human and environment. The Short Form 36 (SF 36), which will be used by researchers in this research, is a measuring instrument to asses the QOL in general. ${ }^{13} \mathrm{SF}$ 36 has 8 health concepts that measure physical health problems, and the effect of health in daily activities. They are limited physical and social activities, role in daily activities due to physical and emotional health problems, psychological health, dynamism, and insight to general health. ${ }^{12}$

Indonesia has lack of research in rehabilitation regarding the mouth and teeth health problems. This is the main drive to initiate this current study. In this occasion, the researchers are interested in assessing the LLLT effects on the QOL of patients who had third molar surgery with accompanying symptoms of pain and trismus. The assessment will be done in two groups, one with LLLT while another without LLLT. Thus, the results will be compared between the two groups before and after the therapy. Since the researchers are motivated to verify other literatures results on the effects of LLLT as a postoperative therapy modality, thus this current study will utilize the recommended parameters.

\section{METHODS}

\section{Participants and Setting}

A RCT, single blind study was performed at the Department of Medical Rehabilitation and Department of Dentistry Oromaxillofacial Surgery Division, Cipto Mangunkusumo National Hospital, Jakarta. It had ethical approval from Research Ethic Commission FKUI and permitted from the Cipto Mangunkusumo National Hospital. Subjects of research were postoperative patients with diagnosis of lower third molar impacted at age 18-30 years on November 2013-May 2014.

\section{Variables}

The inclusion criteria consisted of postoperative patients due to lower third molar unilateral; aged 18-30 years; class II-A impaction (distoangular, mesioangular, horizontal) and II-B (distoangular, mesioangular, horizontal); operation duration less than an hour; no pain killers and antibiotics consumptions in the last 3 days; and have ability to read. During the study, patients were given Amoxicillin-Clavulanat Acid $625 \mathrm{mg}$ and Potassium Diclofenac 50mg in the first 5 days. The surgeons are Senior Resident in the Oromaxillofascial Surgery Division. Patients agreed to follow research program by signing inform consent forms. There were two study groups, the LLLT group and control group (without LLLT). Each sample consisted 21 subjects that were obtained by a randomize table system. The independent variables included age, sex, and impact classes; and dependent variables, which were pain, trismus, QOL. 


\section{Statistical Analysis}

The descriptive data were compared between the two groups using the Chi Square Test. The results are said to be significant statistically if the $\mathrm{p}$ value below 0.05 with confidence interval (CI) of $95 \%$. The data was analyzed by Mann Whitney non-parametric test to see the changes of pain trough visual analogue scale (VAS) and trismus, pain reduction in every therapy. The QOL data (SF-36) that underwent early RAND calculation were tested with Wilcoxon, Man Whitney, and Independent or Paired T-test. These were actually data distribution dependent. The data were processed by SPPS program for windows 17.

\section{RESULTS}

\section{Demographic Characteristics of Research} Subjects

The LLLT group had more male than women subjects while the control group had women predominantly $(\mathrm{p}=0.030, \mathrm{p} \leq 0.05)$ The youngest age of respondent was 18 years old in the control group, and the oldest age was 30 years old on both groups. The most affected area was the right mandible on both groups (57.1\%), however the LLLT group showed higher cases (66.73\%) than the control group (47.6\%). Moreover, both group showed class IIa Mesioangular Impaction (40.5\%).

Table 1. Demographic Characteristics of Research Subjects

\begin{tabular}{|c|c|c|c|c|}
\hline Variables & $\begin{array}{c}\text { LLLT Group } \\
\text { n=21 } \\
\text { n (\%) } \\
\end{array}$ & $\begin{array}{c}\text { Control Group } \\
\mathbf{n}=\mathbf{2 1} \\
\mathbf{n}(\%) \\
\end{array}$ & $\begin{array}{l}\text { Total } \\
N=42 \\
N(\%) \\
\end{array}$ & p value \\
\hline \multicolumn{5}{|l|}{ Sex } \\
\hline - $\quad$ Men & $13(61.9 \%)$ & $6(28.6 \%)$ & $19(45.2 \%)$ & $0.030^{*}$ \\
\hline - Women & $8(38.1 \%)$ & $15(71.4 \%)$ & $23(54.8 \%)$ & \\
\hline \multicolumn{5}{|l|}{ Age } \\
\hline - Mean & $26.90 \pm 2.914$ & $25.52 \pm \mathbf{3 . 6 4 2}$ & $26.21 \pm \mathbf{3 . 3 3 2}$ & 0.182 \\
\hline - $\quad$ Min-max & $21-30$ & $18-30$ & & \\
\hline \multicolumn{5}{|l|}{ Location } \\
\hline - $\quad$ Right Mandible & $14(66.73 \%)$ & $10(47.6 \%)$ & $24(57.1 \%)$ & 0.212 \\
\hline - $\quad$ Left Mandible & $7(33.3 \%)$ & $11(52.4 \%)$ & $18(42.9 \%)$ & \\
\hline \multicolumn{5}{|l|}{ Class of Impaction } \\
\hline - $\quad$ IIa Distoangular & $2(9.5 \%)$ & $5(23.8 \%)$ & $7(16.7 \%)$ & 0.220 \\
\hline - $\quad$ IIa Mesioangular & $10(47.6 \%)$ & $7(33.3 \%)$ & $17(40.5 \%)$ & \\
\hline - IIa Horizontal & $3(14.3 \%)$ & $2(9.5 \%)$ & $5(11.9 \%)$ & \\
\hline - $\quad$ IIb Distoangular & $1(4.8 \%)$ & $4(19.1 \%)$ & $5(11.9 \%)$ & \\
\hline - $\quad$ IIbMesioangular & $2(9.5 \%)$ & $3(14.3 \%)$ & $5(11.9 \%)$ & \\
\hline - $\quad$ IIb Horizontal & $3(14.3 \%)$ & $0(0 \%)$ & $3(7.1 \%)$ & \\
\hline
\end{tabular}

\section{LLLT Effect on Pain Post Impacted Teeth Surgery}

The statistic results on these data were obtained through Mann Whitney Test. Table 2 showed that there was no significant difference on pain sensation in both groups at day 0 as a baseline, although the pain felt by the LLLT group was less $(\mathrm{p}=0.801, \mathrm{p}>0.05)$. On day 7 , there was no pain in the LLLT group, whereas the control group had experienced little pain reduction $(\mathrm{p}=$ $\left.0.000^{*}\right)$. The most significant difference on pain diminution were also seen on day 3 and 7 with $\mathrm{p}=0.000(\mathrm{p} \leq 0.05)$. It can be conclude that the pain reduction was visible (VAS) from day $3^{\text {rd }}$. 
Table 2. LLLT Efect on Pain Post Impacted Teeth Surgery

\begin{tabular}{cccc}
\hline Variables & $\begin{array}{c}\text { LLLT Group } \\
\mathrm{n}=21\end{array}$ & $\begin{array}{c}\text { Control Group } \\
\mathrm{n}=21\end{array}$ & p value \\
\cline { 2 - 3 } & Median & Median & \\
\hline VAS day 0 & $4.8(3-7.8)$ & $4.2(3-8)$ & 0.801 \\
VAS day $3^{\text {rd }}$ & $1(0-3.8)$ & $3(2-5)$ & $0.000^{*}$ \\
VAS day $7^{\text {th }}$ & $0(0-0.2)$ & $1.8(0-4.6)$ & $0.000^{*}$ \\
\hline
\end{tabular}

\section{LLLT Effect on Pain Reduction Post}

Impacted Teeth Surgery

The decreasing pain pattern (delta VAS) was significantly different between the LLLT and
Control groups on day $0-3$, and day 0-7 by using statistic Mann Whitney test $(\mathrm{p} \leq 0.05)$ (Figure 1).

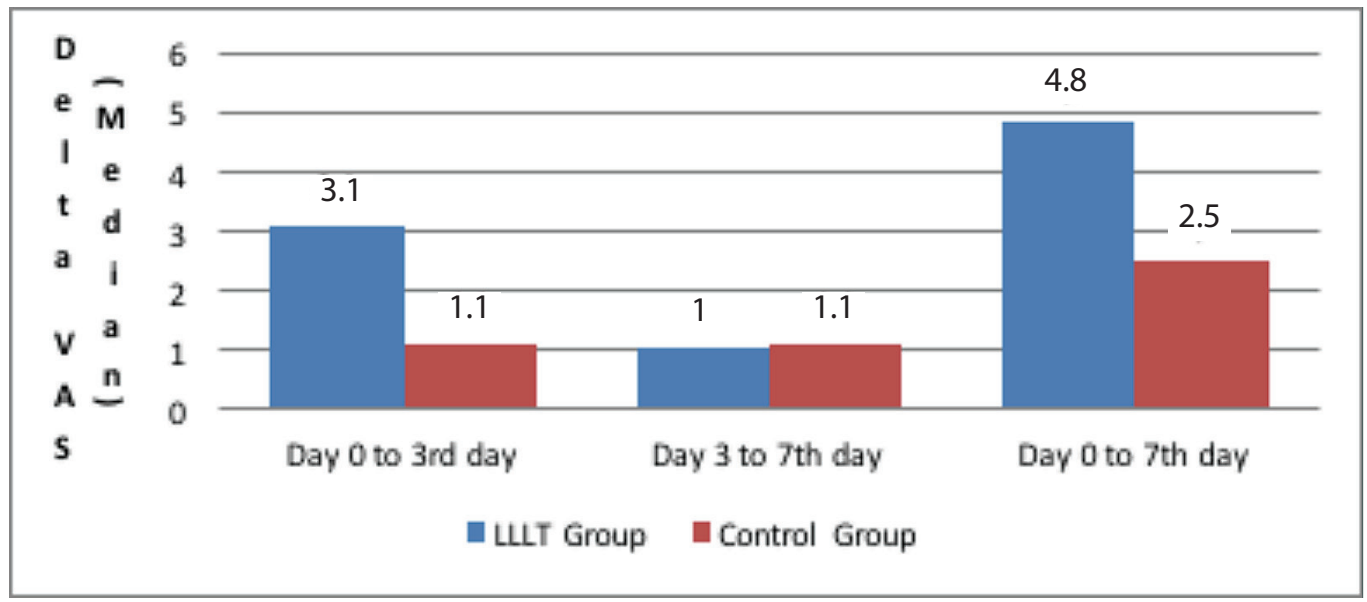

Figure 1. LLLT Effect on Pain Reduction Post Impacted Teeth Surgery

\section{LLLT Effect on Trismus Post Impacted \\ Teeth Surgery}

Baseline Trismus was on day 0 (Table 3). Trismus were decreasing on day 3 with the maximum value was 4 , which mean the absence of Trismus in the LLLT group. On the other hand, the control group showed increased Trismus on day 3. On day 7, the median value of LLLT group is higher (4.2) than the control group (3), which indicated the presence of Trismus in the control group, while none in the LLLT group on day 7. Nonetheless, since the control group had maximum value of 4 , hence, there were subjects who did not have Trismus on day 7.

Table 3. LLLT Effect on Trismus Post Impacted Teeth Surgery

\begin{tabular}{cccc}
\hline Variables & $\begin{array}{c}\text { LLLT Group } \\
\mathrm{n}=21\end{array}$ & $\begin{array}{c}\text { Control Group } \\
\mathrm{n}=21\end{array}$ & p value \\
\cline { 2 - 4 } & Median & Median & \\
\hline Trismus day 0 & $3(1.5-4)$ & $3.4(2.2-4)$ & 0.153 \\
${\text { Trismus day 3 } 3^{\text {rd }}}_{\text {Trismus day } 7^{\text {th }}}$ & $3.5(2.8-4)$ & $2.5(2-3)$ & $0.000^{*}$ \\
\hline
\end{tabular}


Table 3 showed significant differences between the two groups on the presence of Trismus on the third and seventh days $(p=0.000, p<0.05)$. The test used was the Mann Whitney Test. It was evident that LLLT can reduce Trismus.

\section{LLLT Effect on QOL based on Eight Domains of SF-36}

Table 4 showed that significant differences were obvious on the domains of physical function, bodily pain, and general health $(\mathrm{p} \leq 0.05)$ using the Mann Whitney Test. The baseline was the value on the pre therapy in each group.

Table 4. LLLT Effect on QOL based on Eight Domain of SF-36

\begin{tabular}{lccccc}
\hline \multirow{2}{*}{ Variables } & \multicolumn{2}{c}{ LLLT Group } & \multicolumn{2}{c}{ Control Group } & \multirow{2}{*}{ p value } \\
\cline { 2 - 4 } & Pre (Mean) & Post (Mean) & Pre (Mean) & Post (Mean) & \\
\hline Role Physical & 100.00 & 100.00 & 100.00 & 100.00 & 1.000 \\
Physical Function & 78.57 & 92.86 & 76.19 & 83.33 & $0.030^{*}$ \\
Bodily Pain & 57.62 & 95.90 & 54.29 & 67.00 & $0.000^{*}$ \\
General Health & 63.81 & 71.86 & 62.52 & 63.52 & $0.006^{*}$ \\
Vitality & 64.05 & 71.43 & 63.33 & 69.52 & 0.591 \\
Social Function & 77.98 & 79.76 & 81.55 & 81.55 & 0.948 \\
Role Emotion & 80.95 & 96.63 & 77.78 & 85.72 & 0.055 \\
Mental Health & 66.86 & 73.90 & 68.57 & 74.10 & 0.575 \\
\hline
\end{tabular}

\section{LLLT Effect on QOL based on Physical and}

\section{Mental Components of SF-36}

There were increased values on physical and mental components of SF-36 (Figure 2) from pre- to post therapy. The Wilcoxon test revealed significant differences in the LLLT group on both components at pre- and post therapy. Moreover, a significant difference of physical component at post therapy between the two groups was discovered using Independent T-test $(\mathrm{p} \leq 0.05)$.

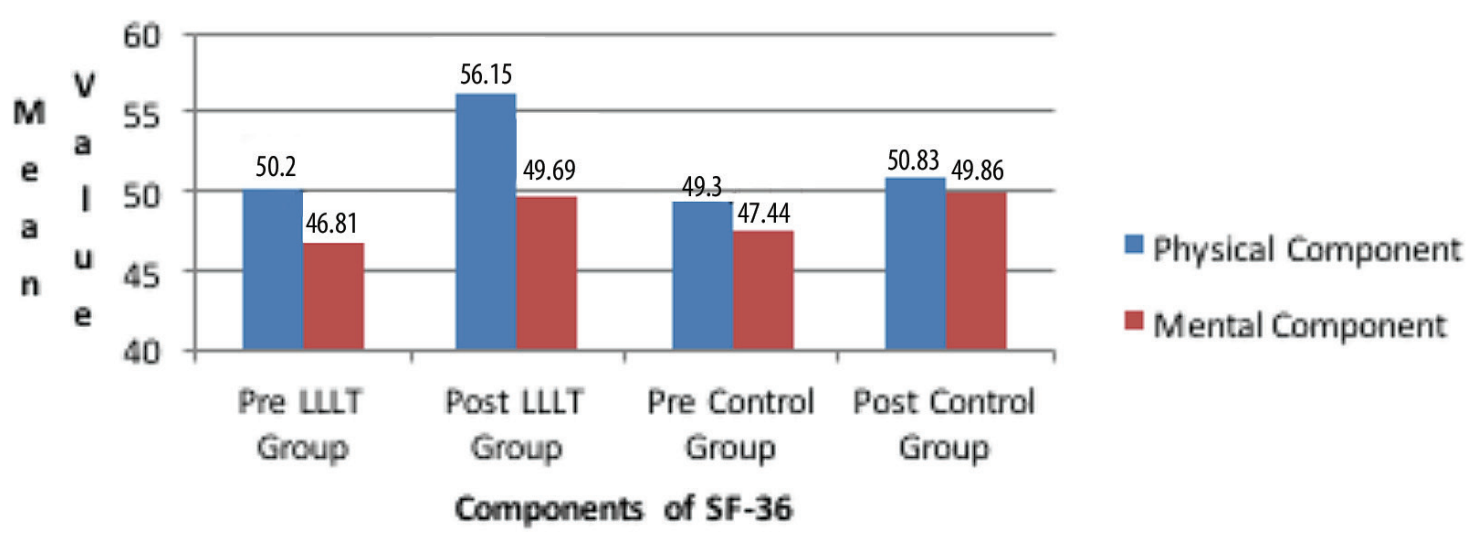

Figure 2. LLLT Effect on QOL based on SF-36 Components 


\section{DISCUSSION}

\section{Demographic Characteristics of Research Subjects}

Number of women subjects who underwent the bottom third molar surgery was significantly greater than men in both groups $(\mathrm{p}=0.03)$. This is consistent with the former research by Soeprapto A (2011) who recorded $57.75 \%$ of subjects were women and $42.3 \%$ were men. Moreover, Hashemipour (2013) documented the ratio of men : women was $1: 1.7$ which was significant. The possible explanation is that women's threshold of pain is lower than men. Nonetheless, prior studies concluded that the predilection is not influenced by sex. ${ }^{5,13}$

This current study exhibited insignificant differenceinage forit's subjects inclusion is 18-30 years of age $($ Mean $=26.21 \pm 3.332)$. Researches by Gbotolorun (2007) and Hashemipour (2013) had almost similar age range with the average age of subjects was $26.63 \pm 7.39$ and 26.2 \pm 5.8 . Moreover, Soeprapto's research (2011) recorded $33.1 \%$ of subjects were in age 19-24 years and $29.6 \%$ in age $25-30$ years. ${ }^{5,10}$ The rationale of 30 years old as the maximum age of subject is because when a person reaches the age of 35 , the ossifying process has taken place. When the surgery is performed at this age, there will be more bones to separate. Thus, produces higher post operative complains, such as severe pain, edema and prolonged tismus. ${ }^{14}$

Indonesia has limited studies about the incidence of molar impacted operation. However, this study demonstrates the common characteristics of patients who have had surgery on the impacted lower third molar. ${ }^{5}$

The most common location of impacted molar is the right mandible (57.1\%) compared to the left mandible (42.9\%). Soeprapto (2011) also stated that $50.4 \%$ of impacted teeth surgery is located in the right mandible. Moreover, previous studies conclude that the most frequent site of impacted molar surgery is in the right mandible $(50.22 \%)$, while left mandible contributes $49.78 \%$ of the cases. Feinmann (1995) explained that the last eruption of lower third molar is on the right mandible. ${ }^{5,15}$

The most frequent class of impaction of lower third molar is the class IIa mesioangular (40.5 \%). This is parallel to Hashemipour (2013) report on the significant number of class IIa cases were about $38.9 \%$ of all classes of third molar impaction. In addition, Quek (2003) found $43.3 \%$ of class IIa impaction. Moreover, Soeprapto studies (2011) recorded about $51.4 \%$ was Mesioangular and the other previous studies found about $43 \%-54.55 \%$. The growth biomechanism of the lower third molar begins inline with the growth of mandible, where angulation moves from horizontal to mesioangular toward vertical. ${ }^{5,12,13,15}$

\section{LLLT Effect on Pain Post Impacted Teeth Surgery}

The LLLT group received activating $\lambda 905$ $\mathrm{nm}$, GaAs, power $100 \mathrm{~mW}$, and doses $18 \mathrm{~J} /$ $\mathrm{cm}^{2}$ obtained significant pain reduction on day $3^{\text {rd }}$ and $7^{\text {th }}$ postoperatively in comparison with the control or Sham-LLLT group. This current study, the LLLT group had meaningful changes of pain on day 0 to 3 , and day 0 to 7 . However, from the $3^{\text {rd }}$ to $7^{\text {th }}$ days there were not significant, because the control group had felt pain until day 7 whereas the LLLT group had pain reduction abruptly. It is possible that the inflammatory process has begun to decrease and disappeared at day 5. Similar results had been reported by Todorovic (2006) and many studies. ${ }^{3,6}$ 
Bello (2011) exhibited significant pain reduction at day $3^{\text {rd }}$ and $4^{\text {th }}$ after surgery $(p \leq 0.05)$. Supporting this, Neckel (2001) also found significant differences $(\mathrm{p} \leq 0.05)$ in pain reduction by administering $11 \mathrm{~J} / \mathrm{cm}^{2}$ Laser Diode, 810nm, intraorally. Amarillas (2011) also reported significant pain reduction betweeh the study group (LLLT $810 \mathrm{~nm}$, power $100 \mathrm{mw}$, $4 \mathrm{~J} / \mathrm{cm}^{2}$ ) and the control group on the $2^{\text {nd }}$ and $7^{\text {th }}$ days postoperatively $(\mathrm{p} \leq 0.05)$.

Nonetheless, in different machine setting, Ferrante (2012) found less meaningful severe pain reduction on day $1^{\text {st }}$ to $3^{\text {rd }}$ between the Laser and Sham-Laser groups with given 980 $\mathrm{nm}$ Diode Laser, $300 \mathrm{~mW}$, and doses $54 \mathrm{~J}$. Taube \& Clokie studies also found insignificant differences in pain reduction with soft Laser between the two group $(\mathrm{p} \geq 0.05)$.

The above evidences are supported by the systematic review of Petersen et al. (2012) who found among 9 studies that assessing the pain between two groups, only 1 study had significantly reduced postoperative pain in the intervention group in comparison with sham group at day 2. The apart from the review, even though the pain reduced clinically, however, it was contradicted statistically. They also reported that the weakness of systematic review was because width of the Laser wavelength, power and doses. ${ }^{2,14}$

\section{LLLT Effect on Trismus Post Impacted Teeth Surgery}

The LLLT group had a significant difference Trismus elimination on day 3 and 7 post operatively in comparison with the group ShamLLLT and the baseline Trismus value was at the day 0. Ferrante research (2012) using similar setting as above, showed significant difference in reducing postoperative Trismus on the $2^{\text {nd }}$ and $7^{\text {th }}$ day $(\mathrm{p} \leq 0.05)$. Amarillas (2011), reported insignificantly Trismus reduction between the two groups with machine setting as above on day 2 and 7 postoperatively. Emshoff et al. (2008) studied Laser with $632.8 \mathrm{~nm}, 30 \mathrm{~mW}, 1.5 \mathrm{~J} / \mathrm{cm} 2$ for 3 times a week showed slight improvement in comparison with the control group in pain and temporomandibula joints Trismus reduction. Moreover, De Abreu et al. (2005) also reported significant Trismus elimination in active Laser group using GaAlAs 780nm..$^{2,6,16}$

In contrast, increase in Trismus had been reported by Bello (2011) and Bruce (1980) which was associated with increasing age, especially above 35 years. Postoperative pain is associated with many mechanic, thermal and chemical stimuli factors that are delivered by $\mathrm{C}$ and $\mathrm{A} \delta$ fibers as the nociceptor. ${ }^{14,17}$ Theoretically, the analgetic effect of LLLT is generated through a biostimulation process that induces stability of double lipid layers conformation, so the stability of the cell membrane can be maintained. Second theory based on in vivo and in vitro researches demonstrated decreasing level of Prostaglandin E-2 (PGE-2) in soft tissue post Laser on temporomandibula area. It is because Laser radiation effects on inhibiting cyclooxygenase-2 (cox-2) thus suppresses the PGE-2 synthesis. ${ }^{2,18}$

\section{LLLT Effect to QOL based on SF-36}

The control group exhibited increase in the QOL on the domain of mental health only. Nonetheless, persistent pain and Trismus deteriorated the improvement of QOL in this group post operatively. This is parallel to Tjakkes et al. (2011) that the Bodily Pain domain of SF-36 affects patient's daily activities. ${ }^{12}$ This current study result on the control group can be explained by Tjakkes et al. (2010) who stated that a patient's psychological state influences 
other pain events. Okeson (2005) hypothesized that during the acute pain, when nociceptive pain occurs affects patient's physical health, and at the final process of acute pain, the psychosocial factors begin to appear to compensate the pain.

The LLLT group demonstrated general QOL improvement, but significant results shown on physical component due to the acute pain. Okeson (2011) reported quite great influence of acute pain on physical health. Petrucci et al. (2011) explained the needed of special assessment in the physical and emotion domains besides scoring pain and temporomandibular joint mobility. ${ }^{12,16}$ The mental health disturbance was also affected by pain and Trismus persistently in the control group. The positive changes of QOL in physical components were faster by LLLT in improving and restoring activities of daily living of patients as usual.

\section{LIMITATION}

This study did not assess the edema and postoperative paresthesia because these two aspects need to be evaluate objectively and properly, and longer duration of treatment. Several subjects of both groups, especially in the control group also complained of swelling on their face during the study. All subjects were given antibiotics and NSAID as the standard treatment to control edema.

\section{CONCLUSION}

LLLT is proven to reduce pain after the lower third molar impacted surgery on day 3 and can completely absent on day 7. It also helps to eliminate Trismus since the day 3 post operatively. The QOL, especially on the physical component of SF-36 is improved by the LLLT. Therefore, LLLT can restore patients' activity daily living patients as usual in a shorter period of time.

\section{REFERENCES}

1. Huang Y, Chen CA, Carroll D. Biphasic Dose Response in LLLT. International Dose Response Society. 2009;1-26.

2. Brignardello PR, Carrasco LA, Araya I, Yanine N, Beyene J, Shah PS. Is Adjuvant Laser Therapy Effective for Preventing Pain, Swelling, and Trismus After Surgical Removal of Impacted Mandibular Third Molars? A Systematic Review and MetaAnalysis. J Oral Maxillofacial Surg. 2012;70:1789-801.

3. Peterson LJ. Principles of Exodontia. In: Peterson LJ, Ellis E, Hupp JR, Tucker MR, editors. Contemporary Oral and Maxillofacial Surgery. $4^{\text {th }}$ ed. Elsevier; 2003. p. $184-220$

4. Coulthard P, Horner K, Sloan P. Master Dentistry: Oral and Maxillofacial Surgery, Radiology, Pathology and Oral Medicine. England: Churchill Livingstone; 2003.

5. Soeprapto A, Julia V, Latif A. Profile of Odontectomy Cases in an Indonesian Teaching Hospital. Journal of Fentistry Indonesia. 2011;18:6-9.

6. Ferrante M, Petrini M, Trentini P, Perfetti G, Spoto G. Effect of Low-Level Laser Therapy After Extraction of Impacted Lower Third Molars. Lasers Med Sci. 2013;28:845-9.

7. Walsh LJ. The Current Status of LLLT in Dentistry. Part 1. Soft tissue applications. Australian Dental Journal. 1997;42:24754.

8. Guideance on the Extraction Wisdom Teeth. National Institute for Clinical 
Excellence. (cited 22 Desember 2012). Available from http//www.nice.org.uk

9. Miloro M. Peterson's of oral and maxillofacial surgery. $2^{\text {nd }}$ ed. London $: B C$ Decker Inc.Hamilton; 2004.

10. Ramirez ML, Perez MA, AlbiolJG, Dominguez JA, Escoda CG. Efficacy of Low-Level Laser Therapy in the Management of Pain, facial Swelling and Postoperative Trismus after a Lower Third Molar Extraction. Laser Med Sci. 2012;27:559-66.

11. Management of Unerupted and Impacted Third Molar Teeth. Scottish Intercollegiate Guidelines Network. (cited 22 Desember 2012). Available from http/www.sign. ac.uk

12. Tjakkes GH, Reinders JJ, Tenvergert EM, Stegenga B. TMD pain : The Effect on Health Related Quality of Life and The Influence of Pain Duration. 2010;8:46.

13. Hashemipour M, Arashlow M, Hanzaei F. Incidence of Impacted Mandibular and Maxillary Third Molars. Med Oral Patologi Cir Buccal. 2013;18:140-5.
14. Bello A, Adeyemo L, Bamghose B, Obi V, Adeyinka A. Effect of Age, Impaction Types and Time on Inflamatory Tissue Reactions Following Lower Third Molar Surgery. Head \& Face Medicine. 2011;7:8.

15. Peterson LJ. Oral and Maxillofacial Surgery. $3^{\text {rd }}$ ed. St. Louis : Mosby Co;1998.

16. Petrucci A, Sgolastra F, Gatto R, Mattei A, Monaco A. Effectiveness of Low-Level Laser Therapy in Temporomandibular Disorders : A Systematic Review and Meta-Analysis. Journal of Orofacial Pain. 2011;25:298-307.

17. Walsh E, Maria S, Eckmann M. Treatment of the Patient with Chronic Pain. In : Frontera WR, editor. Delisa's Physical Medicine and Rehabilitation. $5^{\text {th }}$ ed. Philadelphia : Lippincott Williams \& Wilkins; 2010. p.1273-4.

18. Saliba E, Foreman S. Low Lavel Laser Therapy. In: Prentice WE, editor. Prentice's Therapeutic Modalities in Rehabilitation. $3^{\text {rd }}$ ed. USA: McGraw-Hill Companies; 2005. p.13. 